\title{
Band misplacement: a rare complication of laparoscopic adjustable gastric banding
}

\author{
Konrad Szydłowski, Maciej Michalik, Maciej Pawlak, Maciej Bobowicz, Agata Frask \\ Department of General and Vascular Surgery, Ceynowa Hospital, Wejherowo, Poland
}

Videosurgery and Other Miniinvasive Techniques 2012; 7 (1): 40-44 DOI: $10.5114 /$ wiitm.2011.25930

\begin{abstract}
Introduction: Laparoscopic adjustable gastric banding (LAGB) is considered to be a very effective minimally invasive procedure for treating morbidly obese patients. Nevertheless, there are numerous complications that a good surgeon should be aware of. Most of them have been widely presented in the literature.

Aim: In this study we would like to focus on the rare but important complication which is ante-gastric positioning of the band.

Material and methods: Between January 2005 and May 2008, 122 patients (88 female and 34 male) with mean body mass index (BMI) of $48.5 \mathrm{~kg} / \mathrm{m}^{2}$ (range $35-80 \mathrm{~kg} / \mathrm{m}^{2}$ ) underwent LAGB procedure. The average time of hospitalization was 2.47 days. The first radiological control with band calibration was performed 6 weeks after the operation. Consecutive follow-up depended on the percent excess weight loss (EWL\%).

Results: Of the 122 patients, 4 (3.3\%) presented herein had a band misplaced in the ante-gastric position. There were three out of five surgeons who faced complications of this type. The most and the least experienced team members avoided misplacing the band. Two physicians encountered it at the beginning of their learning curve, and for one it was not related to the process of education. Among other postoperative complications there were two incidents of band slippage, 2 patients had their port localization corrected and in one case drain disconnection occurred. There were no mortalities.

Conclusions: Ante-gastric positioning of the band was the most common cause of obesity surgery failure in our group of patients. It was very difficult to recognize during the typical postoperative checkups; hence there arose a question whether it has been disregarded in other studies.
\end{abstract}

Key words: band misplacement, bariatric surgery, laparoscopic adjustable gastric banding, complications, obesity.

\section{Introduction}

Laparoscopic adjustable gastric banding (LAGB) is a valued bariatric procedure [1-4]. The efficacy of this procedure has been widely presented [5-9]. There is an increasing number of LAGB operations performed worldwide each year [1, 2, 9] and therefore one must analyse all related complications and causes of failure so that they can be easily prevented. Typical problems are already well known and have been fre- quently described [7-13]. In this article, the authors would like to present a rare cause of bariatric surgery failure, which is ante-gastric positioning of the adjustable gastric band.

\section{Material and methods}

Between January 2005 and May 2008, 122 consecutive patients had Swedish Adjustable Gastric Bands implanted because of morbid obesity. All procedures 
were performed in the Department of General and Vascular Surgery, Ceynowa Hospital, Wejherowo, Poland.

All interventions were performed laparoscopically by entering through the pars flaccida of the hepatogastric ligament. The five-trocar standard technique $[6,9]$ was used in each procedure. There were two conversions to open surgery in the whole group.

\section{Technique}

Pneumoperitoneum was achieved via the closed technique with Veress needle insertion and abdomen inflation up to $15 \mathrm{mmHg}$ of $\mathrm{CO}_{2}$. The peritoneal cavity was inspected and all subsequent ports were placed under visual control. The left liver lobe was retracted upward and the lesser curvature of the stomach with the pars flaccid was identified and incised. The right crus of the diaphragm was exposed. The peritoneum was incised at the point intended for placement of the band. The laparoscopic manipulator Goldfinger ${ }^{\circledR}$, Ethicon Endo-Surgery, was introduced through the dissected opening and directed through the retrogastric fat tissue towards the angle of His. In the next steps the fundus of the stomach was released from the diaphragm and the angle of His with the left crus of the diaphragm and earlier implemented Goldfinger ${ }^{\circledR}$ were exposed. The band was tested for proper functioning by immersing it in $\mathrm{NaCl}$ and filling it with air. The band was inserted into the abdomen through the $15-\mathrm{mm}$ trocar. By attaching the band to the Goldfinger ${ }^{\circledR}$, it was pulled around the back of the stomach through the opening on the lesser curvature. The band-end tags were then locked and the access port was connected and fixed.

\section{Patient selection and perioperative period}

In the presented series $72 \%$ (88) of patients were female and 28\% (34) were male. The body mass index (BMI) was in the range of $35-80 \mathrm{~kg} / \mathrm{m}^{2}$ (mean $48.53 \mathrm{~kg} / \mathrm{m}^{2}$ ), and the average time of hospitalization was 2.47 days (2-30 days) (Table I).

Indications for this procedure were $\mathrm{BMI}>40 \mathrm{~kg} / \mathrm{m}^{2}$ or $35 \mathrm{~kg} / \mathrm{m}^{2}$ with concomitant diseases associated with obesity. Prior to surgery each patient had two consultations, during which the level of the patient's motivation was established. All included patients had previously tried a few non-surgical modes of treatment for morbid obesity.

The following examinations were performed before admission:

- abdominal ultrasound scan,
- gastroscopy,

- surgical, endocrinological, anaesthesiological and psychiatric consultations.

During the preoperative period, both antibiotic prophylaxis (premedication with $2 \mathrm{~g}$ of cefazolin i.v.) and antithrombotic prevention (standard dosage regimen of low-molecular-weight heparin LMWH) were given in all cases.

The first radiological control with potential band fill up was performed 6 weeks after surgery. Subsequent control visits were carried out in correlation with the level of excessive weight loss and the appearance of lack of satiety.

\section{Results}

In four of our patients the mispositioned band was found to be in the ante-gastric position, encircling the adipose tissue (Figure $1 \mathrm{~A}-\mathrm{B}$ ).

There were 3 male patients (aged 37, 49 and 50 years with $\mathrm{BMI} 39,48$ and $54 \mathrm{~kg} / \mathrm{m}^{2}$ respectively) and 1 female (aged 31 years with BMI $45 \mathrm{~kg} / \mathrm{m}^{2}$ ). Each patient was hospitalized for 2 days.

Taking into consideration the surgeons in the bariatric team, three out of five had encountered band misplacement. Only two surgeons had avoided this complication. In the case of the third surgeon, who incorrectly implanted the band twice, it happened at the beginning of his learning curve, during the first and the third procedure (Figure 2). Also for the second surgeon the discussed procedure failure occurred at the beginning of the learning process, during the fifth operation (Figure 3). The fourth sur-

Table I. Demographic data of patients who underwent LAGB

\begin{tabular}{|lccc|}
\hline Characteristic & \multicolumn{3}{c|}{ Value } \\
\cline { 2 - 4 } & Female & Male & Total \\
\hline Number of participants & $88(72 \%)$ & $34(28 \%)$ & 122 \\
\hline Mean age [years] & 38.02 & 38.88 & 38.20 \\
\hline Mean height [cm] & 165.49 & 178.63 & 168.29 \\
\hline Mean weight [kg] & 128.38 & 167.94 & 136.82 \\
\hline Mean BMI [kg/m²] & 47.27 & 53.16 & 48.53 \\
\hline $\begin{array}{l}\text { Mean time of } \\
\text { hospitalization [days] }\end{array}$ & 2.43 & 2.63 & 2.47 \\
\hline Mean points in ASA & 1.91 & 2.56 & 2.06 \\
\hline
\end{tabular}



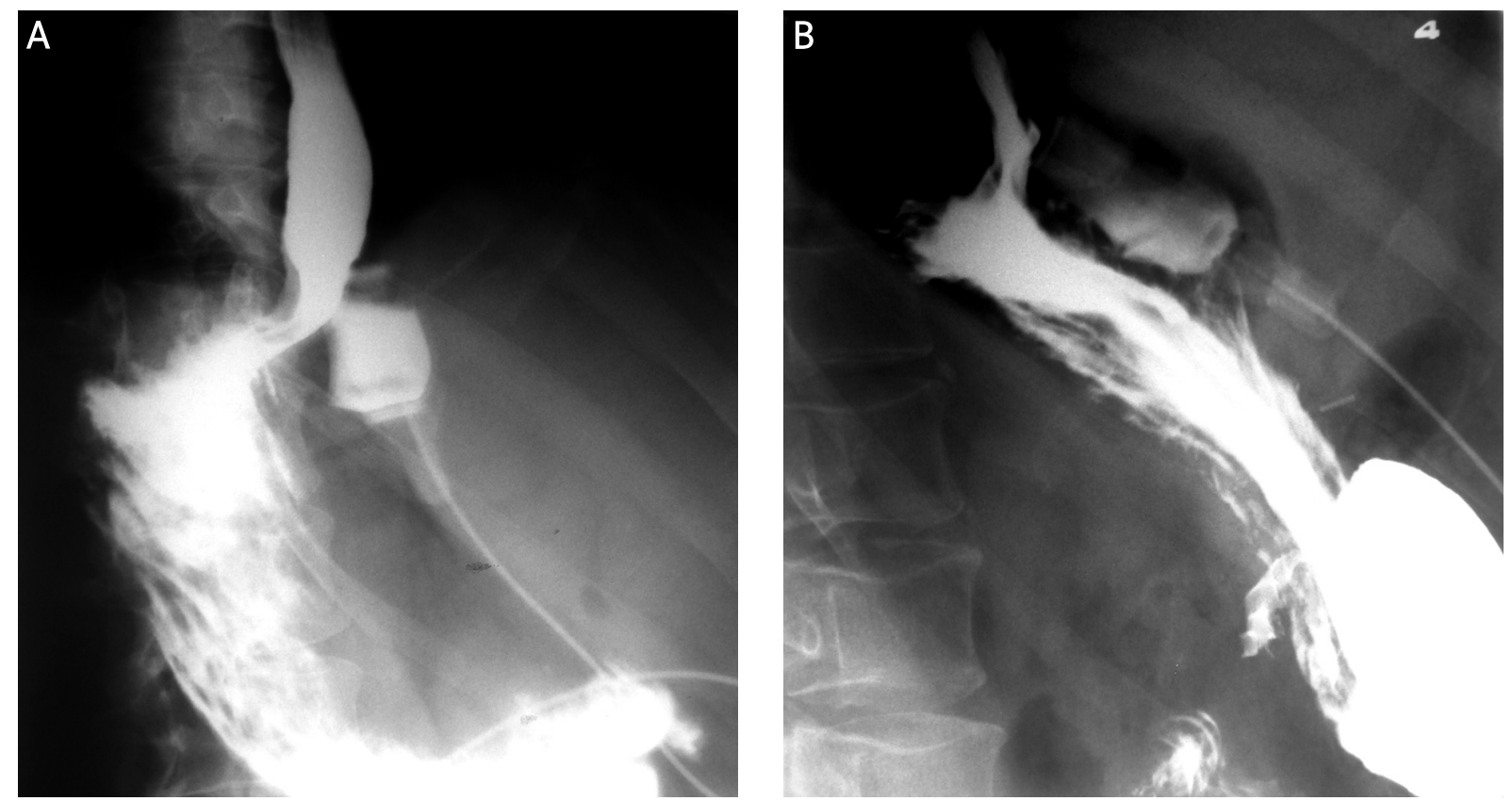

Figure 1 A-B. Chest radiographs with the Barium Swallow showing the band misplacement in the antegastric region

geon encountered band misplacement relatively late, during his $22^{\text {nd }}$ procedure (Figure 4). Among the team, the lead surgeon (number 1) had the greatest experience and the highest number of LAGB operations performed and none of his procedures were followed by this type of complication (Figure 5). The fifth surgeon executed the fewest operations and also did not misplace the band (Figure 6).

Postoperative control and band calibration were performed by two surgeons. Each of 4 patients with the band in the ante-gastric region were subjected to the first check-up 6 weeks after surgery and had their band adjusted based on the assessment of

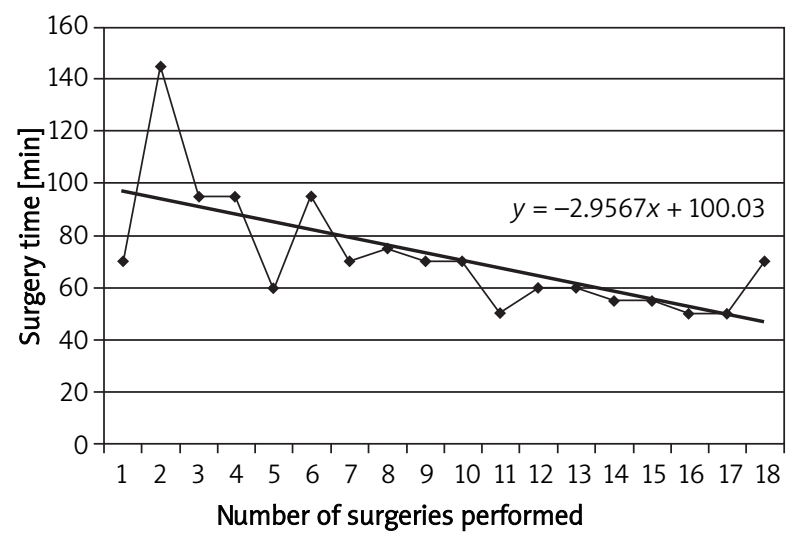

Figure 2. The learning curve for surgeon number 3 excess weight loss. Percent excess weight loss (EWL\%) 6 weeks after surgery was similar for each patient and hold in span of the mean for the whole group, which was $20.36 \%$ (6-36\%).

Furthermore, the barium swallow study indicated impression dependent on the band calibration that did not differ from the radiological image of other participants. It was probably due to band impression on the ventricle cardiac area.

In 3 patients there was no weight change between the first and the second control visit. In one case during the second control the band was adjusted to maximum volume and finally because of insuf-

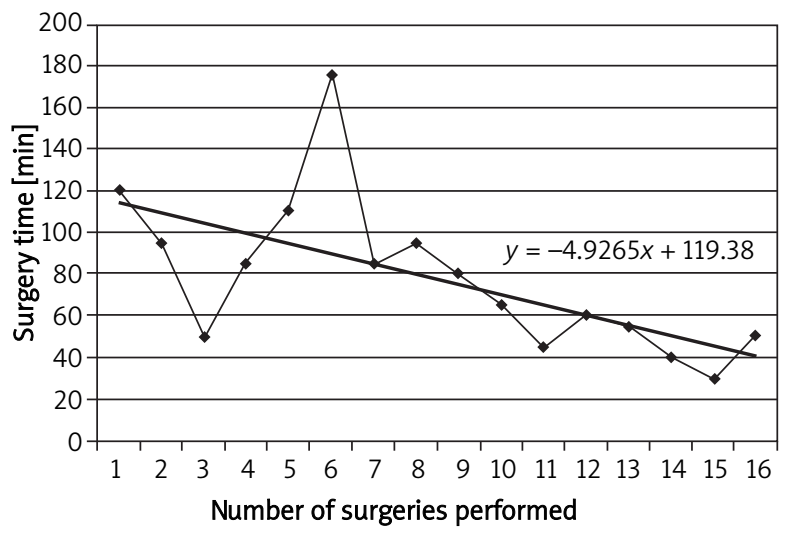

Figure 3. The learning curve for surgeon number 2 


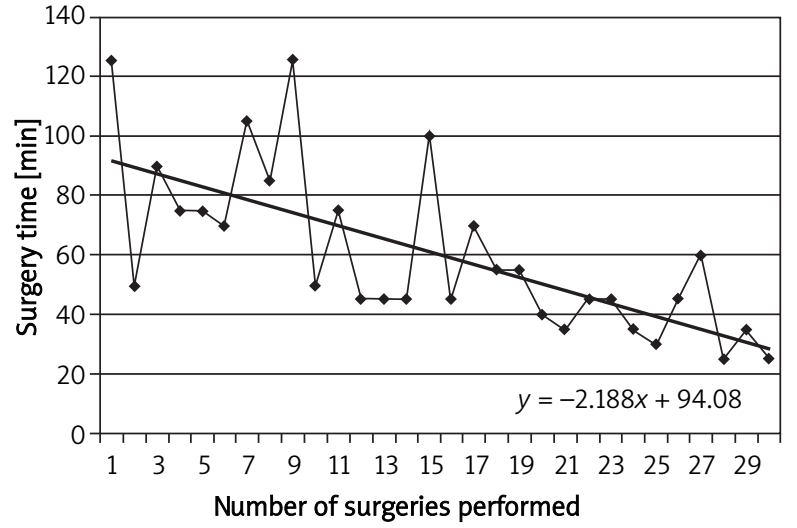

Figure 4. The learning curve for surgeon number 4

ficient results on the third visit the misplacement was identified. Two corrections of the band implantation were done by open surgery, and laparoscopically in two other patients.

Among postoperative complications associated with the band itself, band slippage was observed in 2 cases $(1.7 \%)$. One of the bands slipped near the pyloric region without symptoms and an open procedure was performed to correct its localization. In the second case there was early slippage with gastric frontal wall necrosis, stomach perforation and extensive peritonitis. In this case emergency surgery was performed to remove the band and sleeve resection was done as the alternative bariatric procedure. Two other patients in the presented series had their port localization corrected under local anaesthesia. Disconnection of the port was reported in one case. Reparation was performed laparoscopically. Type and number of other complications were similar to data from other papers [7, 13-16].

\section{Discussion}

Typical complications of LAGB implantation have already been frequently evaluated and presented. Among them, one can list erosion, fluid leakage, band slippage and migration. Additionally, there are complications associated with port and tube connection, for example, leakage, tubing rupture, and disconnection. Last but not least, we can encounter oesophageal dilatation, pouch dilatation and stomach stenosis [7, 10-13, 16-18].

Apart from those, there are rare complications, such as injury of the small [10] or large intestine [11] caused by disconnected tube or obstructive jaundice as the result of incorrect band placement.

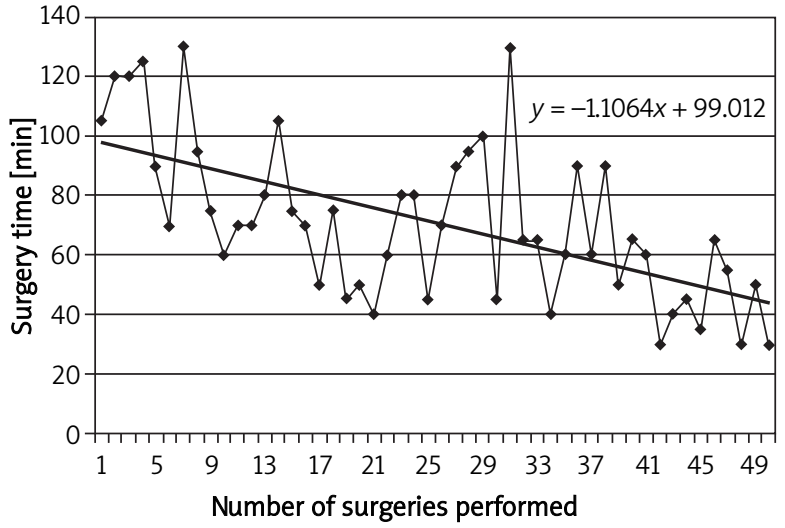

Figure 5. The learning curve for surgeon number 1

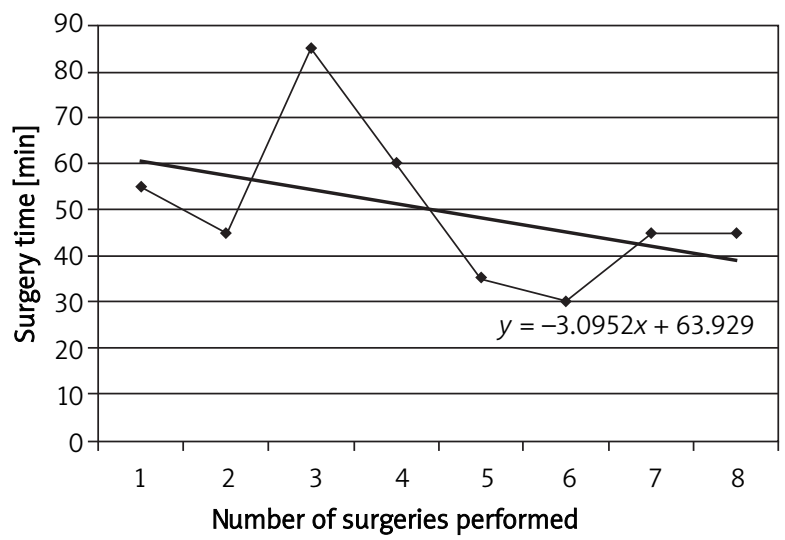

Figure 6. The learning curve for surgeon number 5

The issue of band implantation ante-gastrically has been scarcely analysed in the literature. A Medline search using the phrases 'band misplacement' and 'ante-gastric band implantation' returned only two articles.

The first broached the subject of radiological imaging to diagnose complications after LAGB procedures. Among 218 patients band misplacement was identified in 2 patients $(0.9 \%)$ during the routine radiological follow-up in the first month after the operation [18]. The second article was a case report of a patient with the band implanted around the hepato-duodenal ligament [12]. Only when biliary peritonitis with jaundice was detected 7 months after surgery was the computed tomography and magnetic resonance imaging done and misplacement identified. In the described cases laparotomy was performed to remove the band.

In our material there were four patients in a group of 122 (3.3\%) with incorrect ante-gastric band implantation and it was one of the most common 
adverse events in this series. In comparison, there were only 2 cases $(1.7 \%)$ of band slippage.

Two out of five surgeons in our institution placed the band incorrectly once and it was associated with the learning curve. In one case, the failure occurred late and most likely due to a random event. However, it was avoided by two surgeons, one with the greatest experience who performed the majority of LAGB operations and another with only a few procedures performed.

One can draw interesting conclusions from the timing of the diagnosis of incorrect band localization. During the first control, which usually takes place between the $4^{\text {th }}$ and $6^{\text {th }}$ week after surgery, abnormalities are very difficult to recognize. This is due to similar short-term weight loss results found in all patients. Additionally, radiological images of the barium swallow study were inconclusive.

Surprisingly, patients with band misplacement lost weight in the early stage, probably due to postoperative stress, liquid diet and compression made by swollen tissue and band impression on the ventricle's cardiac region. Furthermore, this could explain the phenomenon of proper barium swallow study, during the first check-up, among patients with band misplacement. Final diagnosis can be made when lack of weight loss occurs and contrast medium is applied directly to the band.

The question that arises is whether it is a very rare adverse event or it is disregarded for different reasons. In some publications, patients with unsatisfactory results after LAGB are recognized [14]. Those patients usually have their bands removed and they are subjected to other procedures. If it was not possible to recognize misplacement during LAGB, hypothetically the band may have been placed incorrectly.

It has been proven that among surgeons performing less than 10 procedures of one kind per year, the number of complications and mortality rate are higher [19]. The number of complications triples in centres with less than 100 bariatric operations performed annually [6]. Therefore these data suggest that band misplacement should be more frequent in the small series being evaluated.

Currently, based on available data, it is difficult to assess the actual number of ante-gastric LAGB implantations. Therefore we submit that band misplacement is a more common cause of bariatric surgery failure than cited in previous medical publications.

\section{References}

1. Stanowski E, Paśnik K. Bariatric Surgery - the current state of knowledge. Videosurgery and Other Miniinvasive Techniques 2008; 3: 71-86.

2. Stanowski E, Wyleżoł M. Paśnik K. Laparoscopy in bariatric surgery in Poland - present status. Videosurgery and Other Miniinvasive Techniques 2007; 2: 18-23.

3. Michalik M, Stanowski E. Outcome of surgical treatment of morbid obesity. Progress in Medicine 2009; 22: 539-44.

4. Steffen R. The history and role of gastric banding. Surg Obes Relat Dis 2008; 4: 7-13.

5. Cunneen SA, Phillips E, Fielding G, et al. Studies of Swedish adjustable gastric band and Lap-Band: systematic review and meta-analysis. Surg Obes Relat Dis 2008; 4: 174-85.

6. Sauerland S, Angrisani L, Belachew M, et al. Obesity surgery. Evidence-based guidelines of the European Association for Endoscopic Surgery (E.A.E.S.). Surg Endosc 2005; 19: 200-21.

7. Zehetner J, Holzinger F, Triaca H, et al. A 6-year experience with the Swedish Adjustable Gastric Band: prospective long-term audit of laparoscopic gastric banding. Surg Endosc 2005; 19: 21-8.

8. Buchwald H, Williams SE. Bariatric surgery worldwide surgery 2003. Obes Surg 2004; 14: 1157-64.

9. Klaiber C, Metzger A, Forsell P. Laparoscopic gastric banding. Chirurgie 2000; 71: 146-15.

10. Zengin K, Sen B, Ozben V, et al. Detachment of the connecting tube from the port and migration into jejunal wall. Obes Surg 2006; 16: 206-7.

11. Hartmann J, Scharfenberg M, Paul M, et al. Intracolonic penetration of the laparoscopic adjustable gastric banding tube. Obes Surg 2006; 16: 203-5.

12. Arkadopoulos N, Palamarou C, Koureas A, et al. Intermittent obstructive jaundice following gastric band placement. Obes Surg 2007; 17: 247-50.

13. Campillo-Soto A, Martín-Lorenzo JG, Lirón-Ruíz R, et al. Evaluation of the clinical pathway for laparoscopic bariatric surgery. Obes Surg 2008; 18: 395-400.

14. Favretti F, Segato G, Ashton D, et al. Laparoscopic adjustable gastric banding in 1,791 consecutive obese patients: 12-year results. Obes Surg 2007; 17: 168-75.

15. Miller KA. Evolution of gastric band implantation and port fixation techniques. Surg Obes Relat Dis 2008; 4: 22-30.

16. Chevallier JM, Zinzindohoué F, Douard R, et al. Complications after laparoscopic adjustable gastric banding for morbid obesity: experience with 1,000 patients over 7 years. Obes Surg 2004; 14 : 407-14.

17. Szydłowski K, Frask A, Michalik M, et al. Complications after surgical treatment of obesity based on own material. Videosurgery and Other Miniinvasive Techniques 2008; 3: 45-52.

18. Mortelé KJ, Pattijn P, Mollet P, et al. The Swedish laparoscopic adjustable gastric banding for morbid obesity: radiologic findings in 218 patients. AJR 2001; 177: 77-84.

19. Courcoulas A, Schuchert M, Gatti G, et al. The relationship of surgeon and hospital volume to outcome after gastric bypass surgery in Pennsylvania: a 3-year summary. Surgery 2003; 134: 613-23. 